University of Nebraska - Lincoln

DigitalCommons@University of Nebraska - Lincoln

Faculty Publications from the Harold W. Manter Laboratory of Parasitology

8-1991

\title{
Syndisyrinx evelinae (Marcus, 1968) n. comb., from the Rock- Boring Urchin, Echinometra lucunter, from St. Barthélemy
}

Lynn Ann Hertel

University of New Mexico

Donald W. Duszynski

University of New Mexico, eimeria@unm.edu

Follow this and additional works at: https://digitalcommons.unl.edu/parasitologyfacpubs

Part of the Parasitology Commons

Hertel, Lynn Ann and Duszynski, Donald W., "Syndisyrinx evelinae (Marcus, 1968) n. comb., from the RockBoring Urchin, Echinometra lucunter, from St. Barthélemy" (1991). Faculty Publications from the Harold W. Manter Laboratory of Parasitology. 171.

https://digitalcommons.unl.edu/parasitologyfacpubs/171

This Article is brought to you for free and open access by the Parasitology, Harold W. Manter Laboratory of at DigitalCommons@University of Nebraska - Lincoln. It has been accepted for inclusion in Faculty Publications from the Harold W. Manter Laboratory of Parasitology by an authorized administrator of DigitalCommons@University of Nebraska - Lincoln. 


\section{Syndisyrinx evelinae (Marcus, 1968) N. Comb., from the Rock-boring Urchin, Echinometra lucunter, from St. Barthélemy}

Lynn A. Hertel and Donald W. Duszynski, Department of Biology, The University of New Mexico, Albuquerque, New Mexico 87131

\begin{abstract}
The umagillid turbellarian Syndesmis evelinae, originally described from unnamed Caribbean sea urchins, is redescribed and placed in the genus Syndisyrinx. Syndisyrinx evelinae n. comb. was found in 8 of $32(25 \%)$ Echinometra lucunter from the Bay of St. Jean, St. Barthélemy; 6 of the $8(75 \%)$ urchins with $S$. evelinae also had Syndisyrinx collongistyla. The major difference between the original description and the worms described here is the structure of the bursal valve. The valve was originally described as having a thickness between the seminal receptacle and the seminal bursa; in fact, the bursal valve has 2 sclerotized ducts, 1 that enters it from the seminal receptacle and another that leads to the bursal canal.
\end{abstract}

Marcus (1968) described an umagillid turbellarian, Syndesmis evelinae, based on 3 specimens from sea urchin(s) he did not name from St. Barthélemy. In 1984, 70 sea urchins representing 5 species from the Grande Cul de Sac and the Bay of St. Jean, St. Barthélemy, were collected and examined for the presence of turbellarians. Urchins examined included 11 Diadema antillarum Philippi, 1845, 44 Echinometra lucunter (Linnaeus, 1758), 6 Echinometra viridis (Agassiz), 3 Eucidaris tribuloides (Lamarck, 1816), and 6 Tripneustes ventricosus (Lamarck, 1816).

Urchins were collected from depths between 0.1 and $3.5 \mathrm{~m}$ and dissected within several hours of collection. All worms were fixed in $10 \%(\mathrm{v} / \mathrm{v})$ formalin in sea water. Entire worms were stained with Grenacher's borax carmine, dehydrated in an ascending ethanol/water series, cleared in toluene, and mounted in Canada balsam. Anatomical measurements were taken from whole mounts using an ocular micrometer in an SBR-K + Nikon microscope at either $100 \times$ or $400 \times$ and, unless otherwise stated, are in micrometers, with means followed by ranges.

None of the $11 \mathrm{D}$. antillarum, $6 \mathrm{E}$. viridis, 3 $E$. tribuloides, and $6 T$. ventricosus from the Grande Cul de Sac or the Bay of St. Jean and none of the $12 \mathrm{E}$. lucunter from the Grande Cul de Sac were found to be infected with turbellarians, whereas 8 of $32(25 \%) E$. lucunter from the
Bay of St. Jean were found to contain $1-4(\bar{x}=$ 2.4) S. evelinae. In 6 of the $8 E$. lucunter, a second worm species was present, Syndisyrinx collongistyla described by Hertel et al. (1990).

The specimens of $S$. evelinae collected in this survey and described below were compared to the original description by Marcus (1968). Unfortunately, to our knowledge no type specimens exist for this species. The worms we collected from E. lucunter from the Bay of St. Jean, St. Barthélemy, differ from those described by Marcus (1968) only in the position and structure of the bursal valve. Marcus (1968) depicted the bursal valve to lie between the seminal bursa and the ovovitelline duct with only a constriction separating the seminal receptacle from the seminal bursa. The worms we examined contained a sclerotized bursal valve with 2 sclerotized ducts, 1 leading from the seminal receptacle to the seminal bursa and the other leading posteriorly from the seminal bursa to the bursal canal. All other anatomical features match those of the worms described by Marcus (1968).

Although this species contains features characteristic of both Syndisyrinx and Syndesmis, we think it properly belongs in Syndisyrinx because it contains more features characteristic of that genus (Kozloff and Westervelt [1987]; also see Hertel et al., [1990] for discussion and literature review). Those features include a narrow, short nearly straight ejaculatory duct; a proportionately long, narrow sclerotized penis stylet that extends to the genital pore; and a relatively narrow male antrum.

A redescription of Syndisyrinx evelinae (Marcus, 1968) n. comb. is as follows. Adult worms (Fig. 1) $(\mathrm{n}=16) 1.6 \times 0.73 \mathrm{~mm}(0.99-2.43 \times$ $0.41-1.00 \mathrm{~mm}$ ) were pink before fixation. Epithelial layer of variable thickness and could fold to give papillate appearance. Cilia of uniform length, $\sim 4$, covering both dorsal and ventral surface. Mouth in anterior $17 \%$ of worm leading to saccate gut. Muscular pharynx round, 143 (90- 


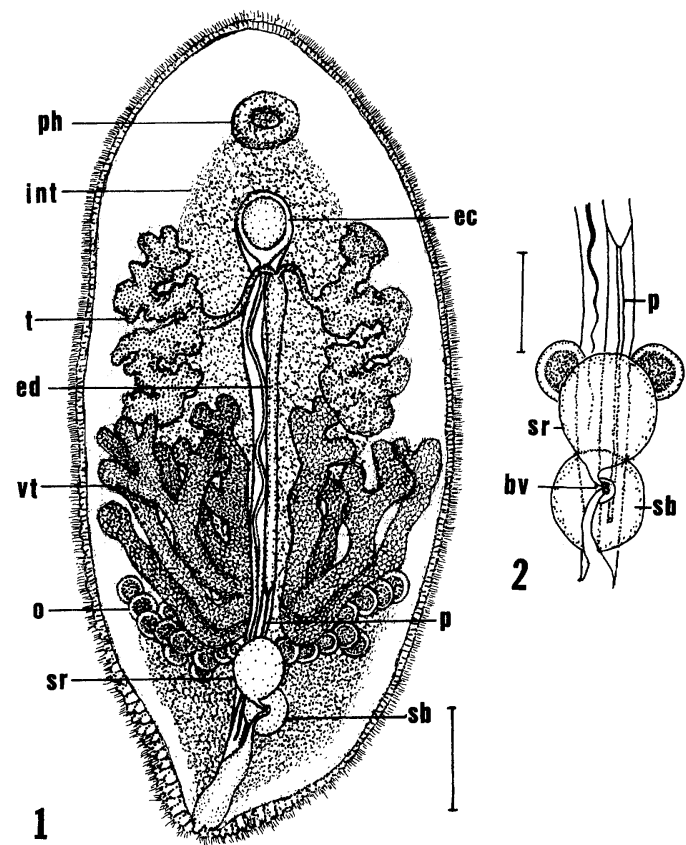

FIgURES 1, 2. Composite line drawings of Syndisyrinx evelinae (Marcus, 1968) n. comb. 1. Composite whole mount. Scale bar, $200 \mu \mathrm{m}$. 2. Enlargement of seminal receptacle and seminal bursa showing details of bursal valve. Scale bar, $100 \mu \mathrm{m}$. Abbreviations (for both figures): bv, bursal valve; ec, egg capsule; ed, ejaculatory duct; int, intestine; $p$, penis stylet; ph, pharynx; $o$, ovary; sb, seminal bursa; sr, seminal receptacle; $t$, testis; and vt, vitellaria.

187 ) in diameter, $20 \%$ of body width. Paired dendritic testes elongate, $399 \times 130(234-546$ $\times 78-250$ ), $25 \%$ of body length and $18 \%$ of body width, with distal border in anterior $27 \%$ of body. Posterior end of testes slightly overlap the anterior border of vitellaria. Vas efferentia lead from testes to slightly dilated anterior end of ejaculatory duct. Ejaculatory duct 372 (200-690) long, $23 \%$ of body length, leading to sclerotized penis stylet 320 (190-368) long and $20 \%$ of body length.

Vitellaria 544 (367-780) long, $34 \%$ of body length, distal border in posterior $25 \%$ of body, and composed of coarse granules arranged in a condensed arborescent configuration with lateral branches converging to 4 thick medial branches that eventually empty into ovovitelline duct.

Paired ovaries, located immediately posterior to vitellaria, are composed of main stem from which originate small branches that overlap vitellaria. Distal end of ovary curves anteriorly while extending to lateral border of worm. Ovaries empty into ovovitelline duct anterior to seminal receptacle.

Uterus extends anterior to vitellaria and posterior to female antrum when filled with egg capsule. Distance from anterior end of uterus to anterior end of ejaculatory duct $13 \%(6-26 \%)$ of body length. Egg capsule $112 \times 83(84-134 \times$ $40-117), 7 \%$ of body length and $12 \%$ of body width, amber in color, with long whiplike filament extending posteriorly.

Seminal receptacle (Fig. 2.) subspherical, 112 $\times 96(74-140 \times 60-150), 7 \%$ of body length and $14 \%$ of body width, with sclerotized duct leading to sclerotized bursal valve of seminal bursa. Seminal bursa (Fig. 2) variable, $102 \times 91(44-$ $160 \times 44-140$ ), $6 \%$ of body length and $13 \%$ of body width. Sclerotized duct leads from bursal valve to bursal canal.

Filament glands located in posterior 4\% (19\%) of body. Products from filament glands empty into female antrum.

A voucher specimen, whole mount, was deposited in the U.S. National Museum as Helm. Coll. No. 81538.

Syndisyrinx evelinae is readily distinguishable from $S$. collongistyla found in the same urchins in that $S$. evelinae elongates and compresses to move whereas $S$. collongistyla simply glides along the surface. A second distinguishing feature is that $S$. evelinae is pink and $S$. collongistyla is red.

We thank Dr. John E. Ubelaker for his constructive comments. We also thank Dr. Eugene S. Hertel and Mr. Donald W. Garland for their help in collecting the urchins.

\section{LITERATURE CITED}

Hertel, L. A., D. W. DuszynSKi, AND J. E. Ubelaker. 1990. Turbellarians (Umagillidae) from Caribbean urchins with a description of Syndisyrinx collongistyla $\mathrm{n}$. sp. Transactions of the American Microscopical Society 109: 273-281.

Kozloff, E. N., AND C. A. Westervelt. 1987. Redescription of Syndesmis echinorum François, 1886 (Turbellaria: Neorhabdocoela: Umagillidae), with comments on distinctions between Syndesmis and Syndisyrinx. Journal of Parasitology 73: 184-193.

Marcus, E. 1968. A new Syndesmis from Saint-Barthélemy, Lesser Antilles (Neorhabdocoela). Studies on the Fauna of Curaçao and other Caribbean Islands 26: 134-142. 